\title{
Opportunities and challenges in the development of kinase inhibitor therapy for cancer
}

\author{
Charles L. Sawyers ${ }^{1}$ \\ Howard Hughes Medical Institute; Departments of Medicine, Molecular and Medical Pharmacology, and Urology; and \\ Jonsson Cancer Center; David Geffen School of Medicine at UCLA, Los Angeles, California 90095, USA
}

The success of the tyrosine kinase imatinib inhibitor (Gleevec, STI571) in treating chronic myeloid leukemia as well as other selected cancers has greatly increased optimism for the broader application of kinase inhibitor therapy in cancer. To date, however, imatinib remains the only spectacularly successful example. Is it simply a matter of time before kinase inhibitors become more broadly useful? Or is chronic myeloid leukemia a unique disease that does not reflect the true genetic complexity of other cancers? Here I address this question by summarizing the growing evidence that kinase inhibitor therapy works consistently and reliably against cancers in which the kinase drug target is constitutively activated by gene mutation. I also discuss the prospects for extending this concept more broadly-to other cancers in which kinase pathways are activated directly by kinase gene mutation or indirectly by loss of negative regulatory proteins (i.e., phosphatases such as the PTEN tumor suppressor). Finally, I give my perspective on how future drug discovery and clinical trial design programs in molecularly targeted therapy could be modified based on present clinical experience with kinase inhibitors.

In May 2001, approval of the first tyrosine kinase inhibitor for the treatment of a human cancer (imatinib/ Gleevec for chronic myeloid leukemia) was greeted with great optimism by the oncology community, with hopes for successful extension of this approach to other malignancies. One year later, the failure of a second tyrosine kinase inhibitor (gefitinib/Iressa), when combined with chemotherapy, to show superiority to standard treatment for lung cancer led to reservations about the promise of kinase inhibitors as anticancer agents. This review is my perspective on where we stand. Building on my experience with the development of imatinib for chronic myeloid leukemia, I summarize why I believe some clinical trials with this class of drugs have succeeded whereas others have failed. Central to my thinking is the

${ }^{1}$ E-MAIL csawyers@mednet.ucla.edu; FAX (310) 206-8502. Article and publication are at http://www.genesdev.org/cgi/doi/10.1101/ gad.1152403. notion of "kinase dependency" states in cancer cells and the challenges inherent in recognizing these tumors in the clinic. I also outline a general strategy for conducting first-in-human, phase I clinical trials of kinase inhibitors that includes molecular enrollment criteria and precise biochemical and biological measures of drug action in tumor cells so that subsequent decisions for clinical development of a novel compound might be more informed.

\section{Present clinical experience with kinase inhibitors}

The imatinib story in $C M L$

Chronic myeloid leukemia (CML) is a myeloproliferative disease caused by constitutive activation of the Abl kinase, as a consequence of fusion to the Bcr gene (Sawyers 1999). This fusion event, originally recognized as the $\mathrm{t}(9,22)$ Philadelphia chromosome translocation, occurs in a pluripotent hematopoietic stem cell and leads to clonal expansion over a period of many years. At the time of diagnosis, patients typically have peripheral blood counts 10-20-fold higher than normal, with an estimated $10^{12}$ or greater tumor cells. Remarkably, most patients have relatively few symptoms despite this dramatic tumor burden, presumably because CML cells retain the ability to differentiate and function essentially as normal hematopoietic cells. At the cytogenetic level, the Philadelphia chromosome is the only abnormality present during the initial stages of the disease /termed the chronic phase), leading to the concept that CML may be a "one hit" disease caused by a single molecular abnormality. With time, however, the disease progresses and is associated with the rather abrupt acquisition of additional cytogenetic abnormalities as well as defects in the differentiation program. This stage, known as the blast crisis, resembles acute leukemia and is rapidly fatal. Thus, a simple model for the molecular pathophysiology of CML is that the disease is initiated by expression of the BCR-ABL fusion protein in a single hematopoietic stem cell, followed by the acquisition, years later, of several second hits that mediate the transition to the blast crisis. A detailed cataloging of these second hits has 
not been reported, but the list includes several genes broadly implicated in cancer such as p53 and the p16/ $A R F$ locus (Ahuja et al. 1989; Foti et al. 1991; Neubauer et al. 1993; Sill et al. 1995).

Imatinib is a small molecule kinase inhibitor that reversibly competes with ATP for binding to the kinase domain of its target proteins. Imatinib was originally isolated in a screen for inhibitors of the platelet-derived growth factor receptor (PDGFR), then subsequently found to have activity against the $\mathrm{Abl}$ and Kit kinases (Buchdunger et al. 1995; Druker et al. 1996). After a remarkable series of preclinical and clinical studies, which have been detailed in other reviews (Druker 2002; Shah and Sawyers 2003), imatinib was approved for the treatment of CML in May 2001. In patients in the chronic phase of the disease, response rates are extremely high. Peripheral blood counts return to normal in $>90 \%$ of patients, and $50 \%-70 \%$ have no evidence of the Philadelphia chromosome translocation in their bone marrow after 3-6 mo of therapy, indicative of a 2-3 log reduction in tumor burden. Subsequent studies using PCR to measure disease burden indicate that nearly all patients still have residual BCR-ABL-expressing cells in the blood (Branford et al. 2002). Although the clinical significance of this finding is unknown at present, it raises the possibility that imatinib alone is not curative therapy. Parallel studies of CML patients treated in the blast crisis indicated that imatinib also had impressive activity in late-stage disease, albeit short-lived because of rapid emergence of drug-resistant cells (Druker et al. 2001a; Sawyers et al. 2002).

These clinical responses in blast crisis patients are particularly interesting because they serve as proof of the concept that pharmacologic targeting of a single molecular lesion can induce responses in cancers with multiple genetic abnormalities. Further evidence comes from studies that have defined the mechanism of resistance to imatinib, which is caused predominantly by mutations in BCR-ABL that prevent the drug from binding to the kinase domain (Gorre et al. 2001; Shah et al. 2002; Branford et al. 2003). Thus, sustained kinase activation through BCR-ABL appears to be the Achilles' heel of CML even in the setting of a bewildering array of other oncogene and tumor suppressor gene abnormalities. Recent data suggest that these $\mathrm{BCR}-\mathrm{ABL}$ mutations predate the initiation of imatinib treatment and presumably reflect mistakes in DNA replication that occur during expansion of the tumor over years. In some cases, the mutant clone has undergone tremendous clonal expansion prior to imatinib treatment, suggesting that the mutant BCR-ABL allele confers a gain of function (Shah et al. 2002). However, there is no direct evidence that these secondary, imatinib-resistance mutations in BCR-ABL play a role in progression from the chronic phase to the blast crisis. Whether these mutations develop because of underlying genetic instability associated with CML progression or simply because of the large number of cell divisions required to generate the leukemic tumor mass (estimated at $>10^{12}$ cells) is unknown.

The clinical data with imatinib in blast crisis CML is remarkably similar to data from murine cancer models expressing inducible transgenes (Chin et al. 1999; Felsher and Bishop 1999). These models provide genetic proof that the initiating oncogenic event may be required for tumor maintenance even at the very latest stages of disease. Because nearly all cancers are presumed to require multiple mutations for initiation and progression, this result in blast crisis CML bodes well for extending kinase inhibitor therapy more broadly (assuming, of course, that the relevant initiating lesion can be identified and targeted).

Other clinical successes with imatinib: targeting Kit and PDGFR

CML is somewhat unique among cancers in that the disease begins in a clinical stage caused by (presumably) a single molecular abnormality. Therefore, the successful application of kinase inhibitor therapy in this setting might be considered a special case. Convincing evidence that the paradigm of kinase inhibitor therapy can be extended more broadly requires clinical success in other cancers. Over the past two years, several examples have fulfilled this promise. Gastrointestinal stromal tumors (GIST) are mesenchymal tumors of the stomach and small intestine (formerly subclassified histologically with leiomyosarcomas) that arise from the intestinal cells of Cajal (Sircar et al. 1999). Unlike most sarcomas, these tumors express the c-kit tyrosine kinase receptor. A significant fraction contain activating point mutations in the juxtamembrane or kinase domain of c-Kit that lead to constitutive kinase activity (Hirota et al. 1998). Furthermore, mice engineered to express such activating kit mutations in the germ line develop tumors that bear remarkable histologic similarity to human GISTs (Sommer et al. 2003). Based on these molecular findings from GIST tumors and the known inhibitory activity of imatinib against c-kit in vitro, clinical studies of imatinib were initiated for GIST patients. Again, beneficial effects were quickly apparent, because a large fraction of patients had complete or partial remissions (van Oosterom et al. 2001; Demetri et al. 2002). One particularly intriguing feature of these responses is the utility of positron emission tomography (PET) scanning using the tracer fluorodeoxyglucose. Prior to treatment, GIST tumors show avid fluorodeoxyglucose uptake, which is substantially reduced after starting imatinib in patients, well in advance of tumor shrinkage based on CT scans (Joensuu et al. 2001). Although the molecular basis for fluorodeoxyglucose update in GIST remains to be defined, these clinical findings serve as a dramatic illustration of the potential for molecular or "functional" imaging.

Because of the molecular heterogeneity of c-kit mutations associated with GIST, it has been possible to correlate distinct molecular lesions with clinical outcome (Singer et al. 2002). First, tumors with detectable c-kit mutations have a greater likelihood of responding to imatinib than those without mutations. Furthermore, tumors with mutations in exon 11 (the juxtamembrane domain) fare best (Heinrich et al., 2003a). The molecular 
basis for differential sensitivity is not clear but could result either from a superior overall prognosis, differential sensitivity to enzymatic inhibition by imatinib, or differences in c-Kit kinase "dependency." Of note, a different c-kit mutation in the activation loop associated with the hematopoietic disorder systemic mastocytosis is completely resistant to inhibition by imatinib, presumably because the mutation occurs in a residue of the kinase domain required for drug binding (Ma et al. 2002). Predictably, imatinib is not generally useful therapy for this disease, but one might envision a more general role for imatinib in targeting nonmalignant mast cells to treat allergic disorders such as asthma. In addition, some GIST tumors respond to imatinib despite the absence of c-Kit gene mutation or expression. The molecular pathophysiology of these apparently paradoxical responses is now explained by the realization that a small subset of GISTs contain mutations in PDGFR $\alpha$ (another imatinib target) instead of c-Kit (Heinrich et al. 2003b).

Imatinib also induces clinical responses in at least three other diseases associated with abnormalities of PDGFR. Patients with chronic myelomonocytic leukemia (CMML) containing the $\mathrm{t}(5 ; 12)$ chromosome translocation express a fusion tyrosine kinase, TEL-PDGFR $\beta$, that functions as a constitutively active kinase, analogous to BCR-ABL (Golub et al. 1994; Sawyers and Denny 1994; Tomasson et al. 1999). Similarly, these patients respond to imatinib in a fashion resembling the responses seen in CML (Apperley et al. 2002). A previously unsuspected PDGFR $\alpha$ fusion protein was recently reported in patients with hypereosinophilic syndrome, who were noted to respond to imatinib without an obvious molecular basis. Gilliland and colleagues uncovered an intrachromosomal deletion on chromosome $4 q 12$ that creates an imatinib-responsive Fip1L1PDGFR $\alpha$ fusion tyrosine kinase (Cools et al. 2003), providing a compelling explanation for the clinical activity observed in this disease. Finally, another sarcoma called dermatofibrosarcoma protuberans is often associated with a $t(17,22)$ chromosomal translocation involving the PDGF ligand, leading to constitutive PDGFR activation through an autocrine loop of constitutive ligand production (Simon et al. 1997; Shimizu et al. 1999). These tumors are also quite sensitive to imatinib (Rubin et al. 2002; Sawyers 2002b). The theme with all these examples, clearly, is that tumors with constitutive activa- tion of any one of the imatinib-sensitive kinase targets have a high likelihood of clinical response. In each case, kinase activation occurs because of a DNA-based abnormality (gene fusion or mutation) in either the gene encoding the kinase or its ligand (Table 1).

\section{Beyond imatinib: early clinical results with other} kinase inhibitors in tumors with kinase abnormalities

A burning question in the kinase inhibitor field is whether the experience with imatinib-responsive cancers will be broadly applicable. Based on the precedent with imatinib, the best test of this hypothesis is in tumors with constitutive kinase activation as a consequence of mutations in the kinase gene itself. Early clinical data using kinase inhibitors to treat cancers that fit this paradigm are beginning to shed some light on the issue. Three examples deserve mention: Flt3, EGFR, and B-Raf (Table 1).

About one-third of acute myeloid leukemias and a smaller fraction of acute lymphoid leukemias contain mutations in the Flt3 receptor tyrosine kinase that lead to activation (Nakao et al. 1996; Kiyoi et al. 1997). These mutant Flt3 alleles are oncogenic in preclinical models and can be inhibited by several different kinase inhibitors that vary in their mechanism of action (Levis et al. 2002; Sawyers 2002a; Weisberg et al. 2002; Armstrong et al. 2003). Clinical trials of three such compounds are in the early stages of phase I or phase II clinical testing, with hints of clinical activity that clearly warrant further evaluation (Foran et al. 2002; Heinrich et al. 2002b; Stone et al. 2002). If the experience with imatinib in blast crisis CML serves as a guide, the prediction is that Flt3 inhibitors will be most active in patients with Flt3 mutations but clinical responses may be transient because of the emergence of resistant subclones. In anticipation of such results, clinical trials of Flt3 inhibitors given in combination with AML-based chemotherapy regimens are under consideration.

A second example is glioblastoma, in which mutations in the epidermal growth factor receptor (EGFR) occur in $\sim 25 \%$ of cases, generally in the context of EGFR amplification (Libermann et al. 1985; Wong et al. 1987, 1992; Frederick et al. 2000; Choe et al. 2003). Unlike the c-kit and Flt3 mutations, which tend to cluster in the juxtamembrane domain or activation loop of the kinase, mu-

Table 1. Examples of mutant kinases in human cancer treated with kinase inhibitors

\begin{tabular}{llll}
\hline Kinase & \multicolumn{1}{c}{ Tumor type } & \multicolumn{1}{c}{ Mechanism of activation } & \multicolumn{1}{c}{ Reference } \\
\hline Abl & CML & Translocation, fusion protein & Sawyers 1999 \\
Kit & GIST & Mutation & Hirota et al. 1998 \\
PDGFRa & GIST & Mutation & Heinrich et al. 2003b \\
& Hypereosinophilic syndrome & Fusion protein & Cools et al. 2003 \\
PDGFRb & Chronic myelomonocytic leukemia & Fusion protein & Golub et al. 1994 \\
Flt3 & Acute myeloid leukemia & Mutation & Kiyoi et al. 1997 \\
& Acute lymphoid leukemia & & Mutation, truncation \\
EGFR & Glioblastoma & Mutation & Frederick et al. 2000 \\
B-Raf & Melanoma & & Davies et al. 2002 \\
\hline
\end{tabular}


tations of EGFR in glioblastoma are typically in frame deletions of exons in the extracellular domain that remove the ligand binding domain, analogous to the retroviral oncogene $\mathrm{v}$-erbB. Most common is deletion of amino acids 6-273 (also called variant III), accounting for $70 \%$ of all EGFR mutations. Others include a truncation at amino acid $958(15 \%)$ or deletion of amino acids $521-$ $603(15 \%)$. For all three examples, the consequence is the same-constitutive EGFR kinase activation. In addition, there is evidence that the mutant allele may also activate a broader spectrum of downstream signal transduction pathways than wild-type EGFR, adding further to its oncogenicity (Huang et al. 1997; Antonyak et al. 1998). The hypothesis that kinase activation by mutation confers sensitivity to kinase inhibitors would predict that EGFR-targeted therapy might be effective in this subset of glioblastoma patients. Indeed, clinical responses were recently reported in $\sim 20 \%$ of glioma patients treated with the small molecule EGFR inhibitor OSI-774 (Tarceva; Prados et al. 2003). However, interpretation of this result is complicated by the unknown status of the EGFR gene in these tumors, the use of antiseizure medications in some patients that can increase the metabolism of OSI-774, and the uncertainty of whether these drugs cross the blood/brain barrier. Future clinical studies can address these issues by mandating molecular analysis of the tumor for kinase mutations and documentation of appropriate drug levels in the serum as well as the tumor tissue. In this way, it should be possible to evaluate "on-target" responses.

Melanoma provides a third example of a tumor with a high frequency of mutations in a kinase (B-Raf). In this case, the link between B-Raf mutations and human cancer was first recognized through a genomics sequencing approach, providing clear evidence of the potential fruit from the human genome project (Davies et al. 2002). Several different mutations have been reported, most of which lead to constitutive Raf kinase activation and cellular transformation. Interestingly, some mutations appear to have reduced kinase activity while enhancing downstream activation of Erk kinases (Wellbrock et al. 2003), suggesting a more complex effect of the mutation on kinase conformation. The parallel clinical development of Raf inhibitors, for more general applications in human cancer, has provided an immediate opportunity to conduct definitive clinical trials in melanomas with Raf mutations. Preclinical studies validate the concept that one Raf inhibitor presently in clinical development is active against human melanomas with B-raf mutations (Choi et al. 2003).

\section{Complications in interpreting clinical results} with kinase inhibitors: gefitinib in lung cancer

Imatinib was initially developed specifically for CML based on the compelling evidence implicating BCR-ABL in the disease, then tested more broadly in additional cancers such as GIST and CMML. In contrast, EGFR inhibitors were initially studied in a range of tumors, such as lung, colon, and head and neck cancers, but were only recently approved for lung cancer after a prolonged debate at the FDA (Cohen et al. 2003). A brief review of this clinical development path is instructive in pointing out potential pitfalls in designing kinase inhibitor trials (for more detailed reviews, see also Burton 2002; Dancey and Freidlin 2003).

Unlike imatinib, the scientific rationale behind the clinical development of EGFR inhibitors was not driven primarily by the presence of EGFR gene mutations in human cancers. In preclinical studies, these drugs showed activity against a broad panel of tumor cell lines expressing EGFR, when given alone or in combination with chemotherapy or radiation. For this reason, phase I studies were not restricted to cancers with a specific molecular abnormality. Rather, patients with a variety of different tumor types were included, and hints of clinical activity were observed in lung and colon tumors (Baselga et al. 2002; Lorusso 2003). At this point, it appears that future clinical development was primarily driven by economic considerations rather than compelling scientific rationale (my opinion). Followup studies in patients with late-stage lung cancer confirmed that EGFR inhibitors (gefitinib/Iressa) can give dramatic clinical results, including complete remissions, but only in a very small fraction of patients (Herbst et al. 2002; Fukuoka et al. 2003). Although these data were eventually convincing enough for FDA approval, it raises the huge question of why only $10 \%$ of lung tumors respond and $90 \%$ do not. Differences in the level of EGFR expression do not appear to be the answer (Cappuzzo et al. 2003). Instead, it is much more likely that these Iressa-responsive tumors have constitutive activation of EGFR (or perhaps another gefitinib-sensitive kinase) caused by a molecular alteration in this signaling pathway that remains to be discovered. Hopefully, this quandary can be resolved quickly, as the answer will immediately guide treatment selection for these patients. In addition, a molecular explanation for these responses could go a long way to counter sentiments often expressed in the media and elsewhere that EGFR inhibitors are a "disappointment" when compared with imatinib because of the low response rates.

The confusion about how well EGFR inhibitors work has increased because it was reported that gefitinib combined with chemotherapy showed no survival advantage over chemotherapy alone in two large, randomized phase III lung cancer trials (Burton 2002; Dancey and Freidlin 2003). Essentially identical conclusions were reached recently in a similar set of trials using a second EGFR inhibitor OSI-774 (Tarceva; Genentech press release, http://www.gene.com/gene/news/press-releases/display. do? method=detail\&id=6648). Until these data are published and correlative molecular studies are completed, we can only speculate about the reasons for the lack of efficacy in this setting. Hopefully, these costly clinical trial mistakes by two different companies will reinforce the key lesson from all kinase inhibitor therapy to datetargeted therapy requires patient selection based on predisposing molecular lesions.

Going forward, several other hypotheses about the rea- 
sons for these failures are worth addressing and will hopefully be instructive for future trial design. First, we must consider the scientific rationale behind combination therapy. One possibility is that inhibition of EGFR will enhance the response to chemotherapy. Precedent comes from breast cancer, in which certain chemotherapeutic agents like cisplatin are more effective when given with the anti-Her2 antibody traztuzamab (Herceptin), but others are not (Pegram et al. 1999). This example is compelling because of the underlying mechanistic rationale proposed: traztuzamab specifically blocked the DNA repair process activated by cisplatin exposure, a concept the authors termed receptor-enhanced chemosensitivity (Pietras et al. 1994). The reverse possibility might also be considered, in which Iressa-resistant lung cancers are rendered sensitive by chemotherapy treatment, although it is difficult to envision a mechanism. Finally, the molecular basis for gefitinib and chemosensitivity may be nonoverlapping, such that the combination would, at best, give additive effects.

Why, then, was no benefit observed in the clinical trials? It is formally possible that chemotherapy could block the action of gefitinib on sensitive tumors, thereby negating the already low response rates with both agents. This might be the case if gefitinib sensitivity requires active cell cycle progression, but there is presently no conclusive evidence to support this contention. An alternative explanation is that the trials were underpowered to detect a difference. If we make the assumption that only patients with gefitinib-sensitive tumors will benefit from the addition of chemotherapy, then just $10 \%$ of all enrolled patients would have been informative. Detecting this difference would obviously require a very large number of patients.

Because present clinical development plans for many other kinase inhibitors also include chemotherapy combinations, it is critical for the oncology drug development community to sort through these issues. To date, most of the rationale leading to these combinations has been empiric, rather than mechanism-based. Clearly, the clinical experiences with gefitinib and OSI-774 should lead to a reevaluation of this approach. A detailed discussion of these complex issues is beyond the scope of this review. Interested readers should consult other recent commentaries for more in-depth analysis (Burton 2002; Dancey and Freidlin 2003; Dancey and Sausville 2003). The premise (and bias) underlying this review, however, is that kinase inhibitors are likely to be effective only in patients with molecular lesions that predispose to kinase dependency. Clinical trials must be designed with this premise in mind.

\section{Challenges for future kinase inhibitor development}

\section{Novel considerations in clinical trial design}

Traditionally, anticancer agents have been evaluated in patients along a very defined path of phase I, phase II, and phase III clinical trials. The goal of phase I testing, the first time a novel agent is administered to humans, is to assess the safety of the drug and define a dose and schedule for phase II testing. These trials proceed by dose escalation, beginning by treating three patients with a dose suspected to be safe based on animal toxicology studies (but often well below the dose expected for clinical activity). Once certain safety parameters have been reached at a certain dose level, three additional patients are treated at the next higher dose level, and so forth. The trial is completed when a toxic dose is reached, and the dose just below is considered the maximum tolerated dose (MTD). The MTD is then used in a larger phase II study to determine the effectiveness of the novel agent against a specific cancer, by measuring the response rate, which is the percentage of patients whose tumor shrinks after receiving treatment. Phase III studies are randomized trials that compare the novel agent to the presently accepted standard treatment for that tumor type, typically using survival as the endpoint. A successful phase III study is usually required for approval by the FDA.

Kinase inhibitors (as well as other molecularly targeted agents) present new challenges for clinical trial design because the typical phase I, phase II, phase III testing paradigm may not fit. In the phase I study of imatinib, dose escalation proceeded to more than three times the dose that first showed clinical efficacy in CML, and the MTD was never fully defined. However, the degree of BCR-ABL kinase inhibition in circulating leukemia cells correlated precisely with the clinically active dose (Druker et al. 2001b). This experience and others have led to the concept that the goal of phase I testing should be to define the biologically effective dose, and document safety at that dose (Fig. 1). Although scientifically logical, this new goal presents formidable technical chal-

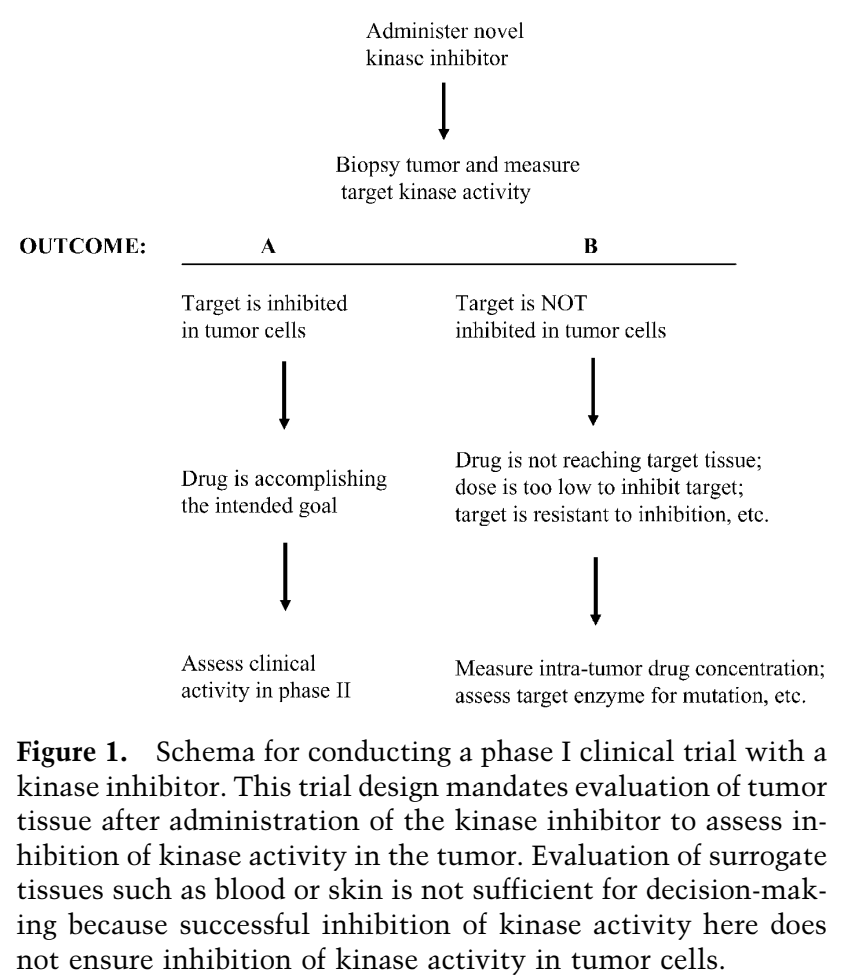

Assess clinical activity in phase I
Measure intra-tumor drug concentration; assess target enzyme for mutation, etc.
Figure 1. Schema for conducting a phase I clinical trial with a kinase inhibitor. This trial design mandates evaluation of tumor tissue after administration of the kinase inhibitor to assess inhibition of kinase activity in the tumor. Evaluation of surrogate ing because successful inhibition of kinase activity here does not ensure inhibition of kinase activity in tumor cells. 
lenges. First, the assays required for measuring target inhibition in clinical tissue have not been fully developed and validated. Experience to date is small and largely based in the laboratories of translational scientists, who have simply adapted existing molecular biological techniques such as immunoblots for use on clinical samples. Widespread application of these approaches in commercial diagnostic laboratories seems unlikely because of the cumbersome nature of these assays.

More clinically accepted assays such as immunohistochemistry and flow cytometry are beginning to be used to measure kinase activation in clinical material /Choe et al. 2003), but they have not been tested extensively in clinical trials. Despite the promise of these reagents, there are concerns about whether reproducible, quantitative measures of target inhibition will be possible. Advances in proteomics could result in powerful new biomarkers that address these needs. A second practical problem in defining biologically effective doses is limited access to tumor tissue in patients with solid tumors. Clearly, molecular evaluation of the tissue will require additional biopsies while receiving treatment. Because this is not the standard of practice in oncology at present, clinical investigators must be creative in trial design to ensure that these critical endpoints can be measured. The molecular imaging field could also address this need by developing probes that measure kinase activation noninvasively. Alternatively, surrogate markers such as hair pigmentation (for c-Kit inhibition) or skin rash (for EGFR inhibition) can be considered, but these may fall short if drug action in tumor cells differs significantly from the surrogate tissue source (Moss et al. 2003).

Another consideration with clinical trials of molecularly targeted agents is whether the definition of response rate in phase II studies, traditionally defined as tumor shrinkage, remains relevant. In the case of CML and GIST, imatinib easily met these traditional criteria, and the drug was approved based on the high response rates in phase II studies. In contrast, a recent study of an antibody targeting the vascular endothelial growth factor (VEGF; bevacizumab/Avastin) in patients with metastatic kidney cancer was effective in delaying disease progression but failed to shrink existing tumor masses (Yang et al. 2003). The molecular rationale for anti-VEGF therapy in this disease is compelling, because $\sim 70 \%$ of kidney cancers contain deletions or mutations of the von Hippel Lindau (VHL) tumor suppressor gene. VHL encodes the ubiquitin ligase for hypoxia-inducible factor (HIF), a transcription factor whose target genes include VEGF. Tumors lacking VHL have high levels of HIF protein expression because of the prolonged half-life of the protein, and, consequently, have increased expression of VEGF and angiogenesis. The clinical result showing that anti-VEGF therapy affects time to progression validates the prediction from molecular studies that VEGF is a relevant therapeutic target in kidney cancer, and provides a valuable treatment option for this disease. However, this study would be deemed a failure according to traditional clinical trial designs that require tumor shrinkage to define response. Because preclinical studies of many targeted agents suggest cytostatic rather than cytotoxic activity, the traditional measure of response may need to be broadened to include disease stabilization. Although conceptually simple, this broader endpoint is fraught with interpretation problems because the rate of progression of most cancers is highly variable, mandating inclusion of a control group.

The most critical issue facing clinical trial design with molecularly targeted agents is patient selection. Traditional inclusion criteria are based on the histology and site of origin of the tumor rather than the molecular phenotype. Logically, a kinase inhibitor should be evaluated in patients with the relevant kinase-dependent cancers, just as imatinib was tested in BCR-ABL-expressing leukemias. With a few exceptions (CML, GIST), the molecular phenotypes of most cancers are not known, and the most appropriate tools for discerning these phenotypes in the context of a clinical trial have not been defined. Strategies under evaluation today include sequencing the target kinase, immunohistochemical analysis of relevant kinase pathways, and mRNA or protein expression profiling to define signatures that correlate with clinical activity (see below). As the experience with gefitinib in lung cancer clearly illustrates, the inability to define the subgroup of patients likely to respond to a novel agent greatly complicates the clinical development path.

\section{Recognizing kinase-dependent cancers}

If we accept the premise that kinase inhibitors will only be successful in kinase-dependent cancers, we face a formidable diagnostic challenge in learning to recognize these tumors in the clinic. If the probability of a tumor being kinase-dependent is contingent on having an activating mutation in the target kinase, then the role of this class of inhibitors could be limited unless the number of cancers that fit this criterion increases dramatically. Based on recent kinome sequencing efforts, there is reason for optimism. As discussed earlier, the significant role of B-Raf mutations in melanoma was not appreciated until these mutations were uncovered through genomics-based sequencing (Davies et al. 2002). Subsequently, mutations in seven different kinases were reported in a limited kinome analysis of colon cancer cell lines and clinical samples (Bardelli et al. 2003). These successes have generated interest in conducting comprehensive kinome sequencing efforts across a spectrum of cancers, which are likely to be completed relatively quickly. These data should provide an accurate estimate of how often human tumors have activating kinase mutations. Related efforts to define the frequency of occult kinase fusion proteins, similar to the Fip1L1-PDGFR example in hypereosinophilic syndrome (Cools et al. 2003), will be similarly informative. Biological validation of the role of these mutations in oncogenicity will take more time, but it is assumed that those found consistently in multiple tumors will be functional.

However, it is important to keep in mind that "kinase dependency" can occur in the absence of a kinase muta- 
tion, as illustrated by the imatinib-sensitive PDGF autocrine loop in dermatofibrosarcoma protuberans discussed earlier. Recognition of tumors where kinase dependency occurs without a kinase mutation will require novel tools beyond kinome sequencing (Fig. 2). Among the potential approaches are proteomic or gene expression profiling strategies that might recognize signatures of kinase dependency. The first iteration of this approach, through the use of phospho-specific antibodies against specific kinase targets or substrates, shows promise in initial immunohistochemical applications (Choe et al. 2003; for review, see Liotta et al. 2003). Limitations include the somewhat tricky performance characteristics of certain antibodies and the potential need for very large numbers of optimized antibodies for comprehensive evaluation. Mass spectroscopy-based proteomics may offer advantages because of its superior sensitivity and specificity, and this technique could be performed on cell lysates enriched for kinase pathway targets by immunoaffinity purification using global antiphosphotyrosine antibodies. Initial proof of concept has been demonstrated in CML cell lines (Salomon et al. 2003), but translation to clinical samples will be challenging. Finally, it may be possible to recognize kinase activation through gene expression profiling (Allander et al. 2001; Shai et al. 2003), despite the fact that these transcriptional changes are several steps downstream from the primary molecular event.

Another putative mechanism for kinase dependency is through loss of a negative regulator of the kinase pathway. The best conceptual example comes from tumors with mutations in the PTEN tumor suppressor gene. This gene, which is mutated or deleted commonly in a

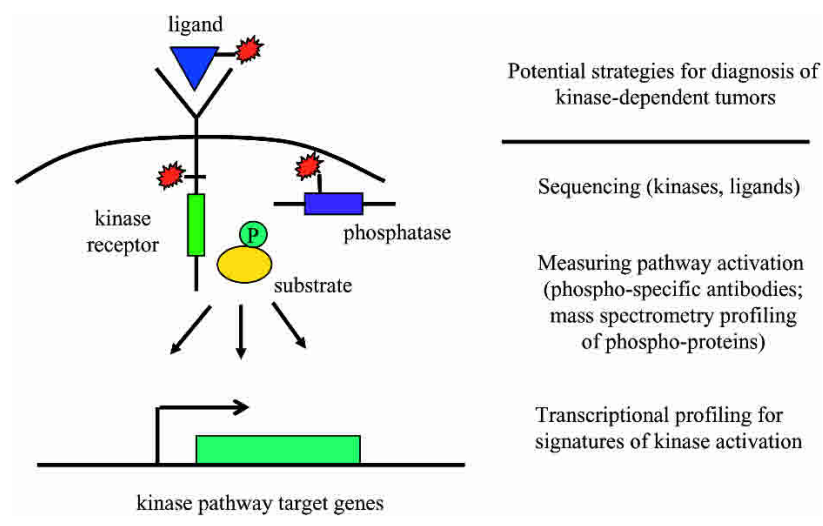

Figure 2. Direct and indirect mechanisms for kinase dependency. Kinase dependency, defined as responsiveness to kinase inhibitor therapy, has been demonstrated in multiple clinical examples in which the kinase target of the inhibitor is constitutively activated by gene mutation or fusion. Additional mechanisms of kinase dependency may include mutations that lead to overproduction of a kinase receptor ligand (as in dermatofibrosarcoma protuberans) or that impair the function of negative regulators such as phosphatases. There are at present no clinical examples that demonstrate kinase dependency due to phosphatase mutations, but trials of mTOR inhibitors in tumors lacking the PTEN phosphatase are ongoing. range of cancers, encodes a lipid phosphatase that regulates signaling through the phosphatidylinositol 3-kinase (PI3-kinase) pathway. Specifically, PTEN dephosphorylates PIP3, the product of PI3-kinase (for reviews, see Cantley and Neel 1999; Vivanco and Sawyers 2002). As a consequence of PTEN loss and the resultant increase in PIP3 levels, signal propagation through downstream kinases such as Akt is constitutively elevated. One question addressed recently in preclinical models is whether this indirect mode of constitutive kinase activation in tumor cells, through loss of a tumor suppressor gene, creates a situation of a kinase dependency analogous to those seen in tumors with direct, activating mutations in the kinase itself. Growing evidence from isogenic human and mouse model systems suggests that this is, indeed, the case.

At present, the most fully developed data set comes from studies using the clinical drug rapamycin or derivatives such as CCI-779 that inhibit the mTOR kinase (Neshat et al. 2001; Podsypanina et al. 2001). Although discovered more than 10 years ago as the target of rapamycin (TOR) in yeast genetic screens (Heitman et al. 1991), the precise function of the TOR proteins (called TOR in yeast, mTOR in mammalian cells) remains to be fully defined. TOR is implicated in the cellular response to nutrients as well as mitogenic growth factors, with continuing debate about the relative importance of these two inputs in TOR regulation (for review, see Schmelzle and Hall 2000; Abraham 2002; Shamji et al. 2003). Until very recently, the connection between mTOR and PI3kinase signaling was tenuous, at best. However, genetic and biochemical evidence from several model systems has now established that Akt can regulate TOR through phosphorylation of the tuberous sclerosis complex (Inoki et al. 2002; Manning et al. 2002; Potter et al. 2002). Hence, tumors with loss-of-function mutations in PTEN have constitutive activation Akt, as well as downstream kinases such as mTOR. Remarkably, these tumors are sensitive to mTOR inhibitors in several different human and murine preclinical models (Neshat et al. 2001; Podsypanina et al. 2001; Grunwald et al. 2002; Shi et al. 2002). In characterizing this type of kinase dependency, perhaps the best concept is that of a synthetic lethal relationship, as originally conceived in yeast. Loss of PTEN creates a synthetic lethal situation in which the mTOR kinase becomes essential for tumor progression but not for the function of most normal cells. Remarkably, this occurs despite the fact that many other critical proliferation and survival pathways downstream of Akt, and other PIP3-regulated signaling pathways, are presumably unaffected by mTOR inhibition. Future work will determine if this PTEN/mTOR relationship holds up in clinical studies in which patient selection is based on presence of a PTEN pathway abnormality in tumor tissue. In the meantime, clinical studies of mTOR inhibitors have demonstrated sporadic activity in various cancers such as renal cell carcinoma (Dancey 2002), but in the absence of any molecular insight into mechanisms of sensitivity. Following the same rationale as the previously mentioned EGFR inhibitor trials in lung cancer, 
phase III randomized studies of mTOR inhibitors alone or in combination with standard therapy have been launched. Perhaps we can already guess the outcome.

Could the synthetic lethal concept for deploying kinase inhibitors be extended more broadly? In the case of PTEN, there are a number of additional kinases deregulated by loss of this tumor suppressor. Intuitively, one might presume that kinases such as PI3-kinase and Akt, that are most directly linked to the primary genetic lesion (PTEN loss), would be the best targets. Initial efforts to develop PI3-kinase and Akt inhibitors have raised concerns about toxicity, because both kinases are clearly crucial for several basic cellular functions (for review, see Brazil et al. 2002; Cantley 2002). However, mouse knockout studies raise the possibility that isoform-specific inhibitors may be safer (Fruman et al. 1999; Suzuki et al. 1999; Chen et al. 2001; Cho et al. 2001; Okkenhaug et al. 2002; for review, see Foukas and Okkenhaug 2003). Interest in these kinase targets remains high, as evidenced by the intensive efforts in the pharmaceutical industry to find such inhibitors.

\section{Selecting lead compounds against kinase targets}

For the past decade, the rules for selecting lead compounds for clinical development from a screen against a specific target kinase have been relatively straightforward. In general, the most desirable characteristics are potency, selectivity, and the ability to synthesize derivatives with drug-like properties (solubility, oral bioavailability, favorable half-life). Based on experience gained with imatinib and other inhibitors, there are several new issues that could/should be considered in the design or selection of future leads from kinase inhibitor programs for clinical development.

One question is whether to bias an in vitro kinase inhibitor screen toward compounds that only bind the kinase in a specific conformation (Fig. 3). This question becomes relevant because imatinib binds ABL when the activation loop is in the inactive or closed configuration (Schindler et al. 2000). Although this feature of imatinib was not appreciated during its original isolation, this property likely explains its relative selectivity for $\mathrm{ABL}$ versus SRC kinases. Indeed, recent crystallographic data show that a dual ABL/SRC inhibitor can bind ABL with the activation loop in the open or closed configuration (Nagar et al. 2002). At present, there is no evidence to suggest that a closed activation loop inhibitor is preferable for drug development, but appreciation of these differences adds additional information to consider when choosing a lead compound for optimization. At a minimum, these structural insights beg the question of whether second-line kinase inhibitors should be directed against a distinct conformation state to prevent the emergence of resistance (discussed below).

Additional insight into the importance of kinase conformation is suggested by the serendipitous discovery of imatinib's clinical activity in hypereosinophilic syndrome. Original clinical reports noted that remissions were observed in this disease using doses that were four

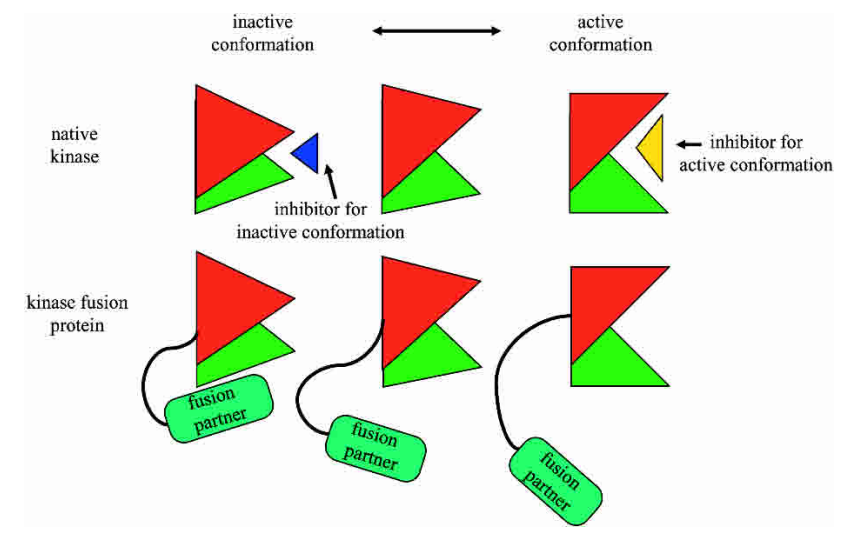

Figure 3. Potential effects of kinase conformation on kinase inhibitor activity. All kinases have two lobes with an activation loop that opens and closes with each round of phosphorylation. The shape of the substrate and ATP-binding sites differs when the kinase is in the active versus inactive conformation, providing an opportunity to isolate inhibitors that may show specificity for a particular kinase conformation. Imatinib, for example, binds exclusively to the inactive conformation of the Abl kinase. The bottom cartoon provides a speculative model for how a fusion partner protein may affect sensitivity to an inhibitor by altering the kinase conformation through allosteric effects. In the example depicted in the cartoon, the fusion partner binds the kinase domain only in the inactive conformation, stabilizing this transition state and allowing greater access to the inhibitor. See text for discussion of the clinical details associated with the effects of imatinib against the FipL1-PRGFR $\alpha$ fusion protein in hypereosinophilic syndrome.

times lower than the dose required for activity in CML or GIST. Once the target Fip1L1-PDGFR fusion protein was identified, the reason for the different dose/response relationships became clear. The Fip1L1-PDGFR fusion is inhibited by a significantly lower dose of imatinib than wild-type PDGFR, ABL, or Kit (Cools et al. 2003). The structural basis for this difference in sensitivity is unknown, but several possibilities are worth considering based on recent structural insights from other kinases. One possibility is that the N-terminal fusion partner alters the conformation of the kinase domain so that it favors imatinib binding, either directly by folding back onto the kinase or indirectly affecting its shape or molecular dynamics. The important point is that the effects of these distal regions of the kinase are rarely considered in the drug discovery phase of present kinase inhibitor programs, in which only the minimally active kinase domain of the target protein is typically included in the screen.

One potentially undesirable consequence of conformation-specific kinase inhibitors may be increased frequency of drug resistance, as illustrated by studies of resistance to imatinib in CML patients. As discussed earlier, the primary mechanism of imatinib resistance in $\mathrm{CML}$ is point mutations in the BCR-ABL kinase, occurring in $>80 \%$ of cases (Shah et al. 2002; Branford et al. 2003). In a few cases, the explanation of how the mutation causes drug resistance is straightforward, because 
the nucleotide change alters an amino acid that makes direct contact with the drug (Gorre et al. 2001). However, a remarkably large number of mutations cause amino acid changes in regions of the kinase quite distant from direct contact sites (Shah et al. 2002; Azam et al. 2003). How, then, do these other mutations cause resistance? When these amino acid substitutions were modeled onto the cocrystal structure of imatinib with $\mathrm{ABL}$, it became clear that these changes restricted the flexibility of the kinase domain required to accommodate imatinib (Shah et al. 2002). Specifically, several mutations localize to the hinge region of the activation loop and presumably alter its ability to close fully. Others occur in the phosphate-binding loop (P-loop), which must achieve a contorted, "induced fit" conformation to accommodate imatinib (Schindler et al. 2000). The P-loop mutations associated with imatinib resistance encode amino acid substitutions that prevent this conformational change through steric hindrance. Finally, some mutations identified by in vitro drug-resistance screens are located outside the kinase domain and presumably exert their effects through allosteric mechanisms (Azam et al. 2003). It will be of interest to learn whether a different inhibitor that is less dependent on this unique ABL kinase conformation would be less prone to the development of resistance.

One final, self-evident lesson from the imatinib trials is that precise specificity of a lead against only the target kinase is clearly not essential. The drug is safe despite activity against three distinct kinase targets (Abl, kit, PDGFR). Rather than discarding a promising compound because of promiscuity against more than one kinase, the toxicology of each new lead still needs to be evaluated on a case-by-case basis. As more and more com- pounds reach the clinical development stage, it should be possible to predict toxicity from chemical structures and in vitro kinase inhibition profiles against a broad panel of targets. Any advance that assists in this process should greatly speed drug development, as the time and expense presently required to evaluate lead compounds severely limit the number that can be developed clinically.

\section{Expectations}

If we look ahead to an era of molecularly based cancer diagnostics coupled with a wide selection of kinase inhibitors, what degree of clinical success might we anticipate? For cancers like CML and GIST, where the kinase abnormality is thought to play an initiating role, partial or complete remissions should be possible if the drug effectively inhibits its kinase target without significant toxicity. The major obstacles are likely to be the emergence of drug resistance, which would be managed best by combination therapy with a second agent whose choice would be based on the mechanism of resistance. With CML, this might be a second BCR-ABL kinase inhibitor. Conversely, there are likely to be other cancers in which the kinase abnormality occurs late during tumor progression and may be present in only a subset of the tumor cells. The clinical expectation here would be a partial remission followed by relapse due to continued growth of a subclone lacking the relevant molecular lesion (Fig. 4). Finally, there may be cases in which the beneficial effect of a kinase inhibitor on a relevant target is overcome by a second genetic lesion in a compensatory signaling pathway. Indeed, the sensitivity of a breast cancer cell line to an EGFR inhibitor is reversed when
Figure 4. Possible clinical outcomes with kinase inhibitors in cancers with multiple genetic abnormalities. The cartoon depicts four different scenarios in which the anticipated response to a kinase inhibitor depends on the nature and timing of the oncogenic event being targeted. The simplest example (far left) predicts a complete response when a kinase inhibitor is used in a disease in which mutation of the target kinase is the initiating event (green cells), as in chronic myeloid leukemia. In the remaining examples, secondary oncogenic events involving kinases (yellow or red cells) occur in addition to the initiating event. The secondary events can occur independently in different clones or sequentially in the same clone. Inhibitors directed against the initiating event are likely to induce complete responses, whereas inhibitors against the secondary events are expected to induce partial remissions, followed by regrowth of a subclone expressing a distinct secondary oncogenic event. The complexity of these various outcomes highlights the need for a precise molecular understanding of the nature and timing of the molecular events in cancer to guide treatment decisions.

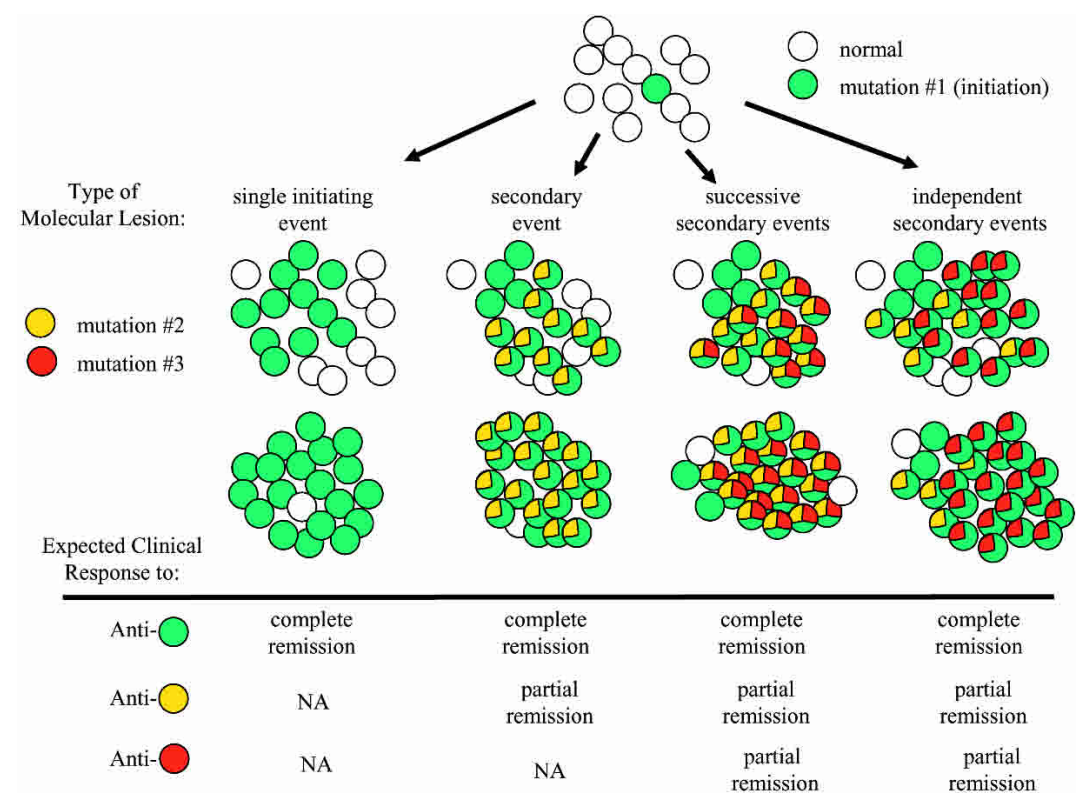


coupled with loss of the PTEN tumor suppressor gene (Bianco et al. 2003). The message, quite clearly, is that the optimum use of kinase inhibitors in oncology can only be achieved if coupled with detailed molecular characterization of tumor tissues. Presently, the ability to conduct this characterization uniformly across clinical trials is the rate-limiting step to rapid progress.

\section{Acknowledgments}

I thank Ingo Mellinghoff for careful reading of the manuscript and members of my laboratory for provocative discussions. Work in my laboratory is supported by the Howard Hughes Medical Institute, Doris Duke Charitable Trust, Leukemia and Lymphoma Society, National Cancer Institute, the Department of Defense, CapCURE, and Accelerate Brain Cancer Cure.

\section{References}

Abraham, R.T. 2002. Identification of TOR signaling complexes: More TORC for the cell growth engine. Cell 111: 912.

Ahuja, H., Bar-Eli, M., Advani, S.H., Benchimol, S., and Cline, M.J. 1989. Alterations in the p53 gene and the clonal evolution of the blast crisis of chronic myelocytic leukemia. Proc. Natl. Acad. Sci. 86: 6783-6787.

Allander, S.V., Nupponen, N.N., Ringner, M., Hostetter, G., Maher, G.W., Goldberger, N., Chen, Y., Carpten, J., Elkahloun, A.G., and Meltzer, P.S. 2001. Gastrointestinal stromal tumors with KIT mutations exhibit a remarkably homogeneous gene expression profile. Cancer Res. 61: 8624-8628.

Antonyak, M.A., Moscatello, D.K., and Wong, A.J. 1998. Constitutive activation of c-Jun $\mathrm{N}$-terminal kinase by a mutant epidermal growth factor receptor. J. Biol. Chem. 273: 28172822.

Apperley, J.F., Gardembas, M., Melo, J.V., Russell-Jones, R., Bain, B.J., Baxter, E.J., Chase, A., Chessells, J.M., Colombat, M., Dearden, C.E., et al. 2002. Response to imatinib mesylate in patients with chronic myeloproliferative diseases with rearrangements of the platelet-derived growth factor receptor $\beta$. N. Engl. J. Med. 347: 481-487.

Armstrong, S.A., Kung, A.L., Mabon, M.E., Silverman, L.B., Stam, R.W., Den Boer, M.L., Pieters, R., Kersey, J.H., Sallan, S.E., Fletcher, J.A., et al. 2003. Inhibition of FLT3 in MLL. Validation of a therapeutic target identified by gene expression based classification. Cancer Cell 3: 173-183.

Azam, M., Latek, R.R., and Daley, G.Q. 2003. Mechanisms of autoinhibition and STI-571/imatinib resistance revealed by mutagenesis of BCR-ABL. Cell 112: 831-843.

Bardelli, A., Parsons, D.W., Silliman, N., Ptak, J., Szabo, S., Saha, S., Markowitz, S., Willson, J.K., Parmigiani, G., Kinzler, K.W., et al. 2003. Mutational analysis of the tyrosine kinome in colorectal cancers. Science 300: 949.

Baselga, J., Rischin, D., Ranson, M., Calvert, H., Raymond, E., Kieback, D.G., Kaye, S.B., Gianni, L., Harris, A., Bjork, T., et al. 2002. Phase I safety, pharmacokinetic, and pharmacodynamic trial of ZD1839, a selective oral epidermal growth factor receptor tyrosine kinase inhibitor, in patients with five selected solid tumor types. I. Clin. Oncol. 20: 42924302.

Bianco, R., Shin, I., Ritter, C.A., Yakes, F.M., Basso, A., Rosen, N., Tsurutani, J., Dennis, P.A., Mills, G.B., and Arteaga, C.L. 2003. Loss of PTEN/MMAC1/TEP in EGF receptor-expressing tumor cells counteracts the antitumor action of EGFR tyrosine kinase inhibitors. Oncogene 22: 2812-2822.

Branford, S., Walsh, S., Rudzki, Z., Grigg, A., Taylor, K., Durrant, S., Arthur, C., Browett, P., Schwarer, A., Ma, D., et al. 2002. Imatinib produces significantly superior molecular responses compared to interferon plus low dose Ara-C in patient with newly diagnosed chronic myeloid leukaemia in chronic phase. Proc. Am. Soc. Hematology Abstr.: 352.

Branford, S., Rudzki, Z., Walsh, S., Parkinson, I., Grigg, A., Szer, J., Taylor, K., Herrmann, R., Seymour, J.F., Arthur, C., et al. 2003. Detection of BCR-ABL mutations in patients with CML treated with imatinib is virtually always accompanied by clinical resistance, and mutations in the ATP phosphatebinding loop (P-loop) are associated with a poor prognosis. Blood 102: 276-283.

Brazil, D.P., Park, J., and Hemmings, B.A. 2002. PKB binding proteins. Getting in on the Akt. Cell 111: 293-303.

Buchdunger, E., Zimmermann, J., Mett, H., Meyer, T., Muller, M., Regenass, U., and Lydon, N.B. 1995. Selective inhibition of the platelet-derived growth factor signal transduction pathway by a protein-tyrosine kinase inhibitor of the 2-phenylaminopyrimidine class. Proc. Natl. Acad. Sci. 92: $2558-2562$.

Burton, A. 2002. What went wrong with Iressa? Lancet Oncol. 3: 708.

Cantley, L.C. 2002. The phosphoinositide 3-kinase pathway. Science 296: 1655-1657.

Cantley, L.C. and Neel, B.G. 1999. New insights into tumor suppression: PTEN suppresses tumor formation by restraining the phosphoinositide 3-kinase/AKT pathway. Proc. Natl. Acad. Sci. 96: 4240-4245.

Cappuzzo, F., Gregorc, V., Rossi, E., Cancellieri, A., Magrini, E., Paties, C.T., Ceresoli, G., Lombardo, L., Bartolini, S., Calandri, C., et al. 2003. Gefitinib in pretreated non-small-cell lung cancer (NSCLC): Analysis of efficacy and correlation with HER2 and epidermal growth factor receptor expression in locally advanced or metastatic NSCLC. J. Clin. Oncol. 21: 2658-2663.

Chen, W.S., Xu, P.Z., Gottlob, K., Chen, M.L., Sokol, K., Shiyanova, T., Roninson, I., Weng, W., Suzuki, R., Tobe, K., et al. 2001. Growth retardation and increased apoptosis in mice with homozygous disruption of the Akt1 gene. Genes \& Dev. 15: 2203-2208.

Chin, L., Tam, A., Pomerantz, J., Wong, M., Holash, J., Bardeesy, N., Shen, Q., O'Hagan, R., Pantginis, J., Zhou, H., et al. 1999. Essential role for oncogenic Ras in tumour maintenance. Nature 400: 468-472.

Cho, H., Mu, J., Kim, J.K., Thorvaldsen, J.L., Chu, Q., Crenshaw III, E.B., Kaestner, K.H., Bartolomei, M.S., Shulman, G.I., and Birnbaum, M.J. 2001. Insulin resistance and a diabetes mellitus-like syndrome in mice lacking the protein kinase Akt2 (PKB beta). Science 292: 1728-1731.

Choe, G., Horvath, S., Cloughesy, T.F., Crosby, K., Seligson, D., Palotie, A., Inge, L., Smith, B.L., Sawyers, C.L., and Mischel, P.S. 2003. Analysis of the phosphatidylinositol 3'-kinase signaling pathway in glioblastoma patients in vivo. Cancer Res. 63: $2742-2746$.

Choi, Y.-J., Fanidi, A., White, S., Lyons, J., Wilhelm, S., Wang, Q., and Bollag, G. 2003. The novel Raf inhibitor BAY 439006 blocks signaling and proliferation in BRAF mutant and wildtype melanoma and coloretal tumor cell lines. Proc. Am. Assoc. Cancer Res. Abstr.: 270.

Cohen, M.H., Williams, G.A., Sridhara, R., Chen, G., and Pazdur, R. 2003. FDA drug approval summary: gefitinib (ZD1839) (Iressa) tablets. Oncologist 8: 303-306.

Cools, J., DeAngelo, D.J., Gotlib, J., Stover, E.H., Legare, R.D., Cortes, J., Kutok, J., Clark, J., Galinsky, I., Griffin, J.D., et al. 
2003. A tyrosine kinase created by fusion of the PDGFRA and FIP1L1 genes as a therapeutic target of imatinib in idiopathic hypereosinophilic syndrome. N. Engl. J. Med. 348: $1201-1214$.

Dancey, J.E. 2002. Clinical development of mammalian target of rapamycin inhibitors. Hematol. Oncol. Clin. North Am. 16: $1101-1114$

Dancey, J.E. and Freidlin, B. 2003. Targeting epidermal growth factor receptor-Are we missing the mark? Lancet 362: 6264.

Dancey, J. and Sausville, E.A. 2003. Issues and progress with protein kinase inhibitors for cancer treatment. Nat. Rev. Drug Discov. 2: 296-313.

Davies, H., Bignell, G.R., Cox, C., Stephens, P., Edkins, S., Clegg, S., Teague, J., Woffendin, H., Garnett, M.J., Bottomley, W., et al. 2002. Mutations of the BRAF gene in human cancer. Nature 417: 949-954.

Demetri, G.D., von Mehren, M., Blanke, C.D., Van den Abbeele, A.D., Eisenberg, B., Roberts, P.J., Heinrich, M.C., Tuveson, D.A., Singer, S., Janicek, M., et al. 2002. Efficacy and safety of imatinib mesylate in advanced gastrointestinal stromal tumors. N. Engl. J. Med. 347: 472-480.

Druker, B.J. 2002. Perspectives on the development of a molecularly targeted agent. Cancer Cell 1: 31-36.

Druker, B.J., Tamura, S., Buchdunger, E., Ohno, S., Segal, G.M., Fanning, S., Zimmermann, J., and Lydon, N.B. 1996. Effects of a selective inhibitor of the Abl tyrosine kinase on the growth of Bcr-Abl positive cells. Nat. Med. 2: 561-566.

Druker, B.J., Sawyers, C.L., Kantarjian, H., Resta, D.J., Reese, S.F., Ford, J.M., Capdeville, R., and Talpaz, M. 2001a. Activity of a specific inhibitor of the BCR-ABL tyrosine kinase in the blast crisis of chronic myeloid leukemia and acute lymphoblastic leukemia with the Philadelphia chromosome. $N$. Engl. J. Med. 344: 1038-1042.

Druker, B.J., Talpaz, M., Resta, D.J., Peng, B., Buchdunger, E., Ford, J.M., Lydon, N.B., Kantarjian, H., Capdeville, R., OhnoJones, S., et al. 2001b. Efficacy and safety of a specific inhibitor of the BCR-ABL tyrosine kinase in chronic myeloid leukemia. N. Engl. J. Med. 344: 1031-1037.

Felsher, D.W. and Bishop, J.M. 1999. Reversible tumorigenesis by MYC in hematopoietic lineages. Mol. Cell 4: 199-207.

Foran, J., O'Farrell, A.-M., Fiedler, W., Serve, H., Paquette, R., Cooper, M., Heinrich, M.C., Kim, H., Yuen, H.A., Louie, S.G., et al. 2002. An innovative single dose clinical study shows potent inhibition of FLT3 phosphorylation by SU11248 in vivo; A clinical and pharmocodynamic study in AML patients. Proc. Am. Soc. Hematology Abstr.: 2196.

Foti, A., Ahuja, H.G., Allen, S.L., Koduru, P., Schuster, M.W., Schulman, P., Bar-Eli, M., and Cline, M.J. 1991. Correlation between molecular and clinical events in the evolution of chronic myelocytic leukemia to blast crisis. Blood 77: 24412444.

Foukas, L.C. and Okkenhaug, K. 2003. Gene-targeting reveals physiological roles and complex regulation of the phosphoinositide 3-kinases. Arch. Biochem. Biophys. 414: 13-18.

Frederick, L., Wang, X.Y., Eley, G., and James, C.D. 2000. Diversity and frequency of epidermal growth factor receptor mutations in human glioblastomas. Cancer Res. 60: 13831387.

Fruman, D.A., Snapper, S.B., Yballe, C.M., Alt, F.W., and Cantley, L.C. 1999. Phosphoinositide 3-kinase knockout mice: Role of p85alpha; in B cell development and proliferation. Biochem. Soc. Trans. 27: 624-629.

Fukuoka, M., Yano, S., Giaccone, G., Tamura, T., Nakagawa, K., Douillard, J.Y., Nishiwaki, Y., Vansteenkiste, J., Kudoh, S., Rischin, D., et al. 2003. Multi-institutional randomized phase II trial of gefitinib for previously treated patients with advanced non-small-cell lung cancer. J. Clin. Oncol. 21: 2237-2246.

Golub, T.R., Barker, G.F., Lovett, M., and Gilliland, D.G. 1994. Fusion of PDGF receptor $\beta$ to a novel ets-like gene, tel, in chronic myelomonocytic leukemia with $\mathrm{t}(5 ; 12)$ chromosomal translocation. Cell 77: 307-316.

Gorre, M.E., Mohammed, M., Ellwood, K., Hsu, N., Paquette, R., Rao, P.N., and Sawyers, C.L. 2001. Clinical resistance to STI-571 cancer therapy caused by BCR-ABL gene mutation or amplification. Science 293: 876-880.

Grunwald, V., DeGraffenried, L., Russel, D., Friedrichs, W.E., Ray, R.B., and Hidalgo, M. 2002. Inhibitors of mTOR reverse doxorubicin resistance conferred by PTEN status in prostate cancer cells. Cancer Res. 62: 6141-6145.

Heinrich, M.C., Druker, B.J., Curtin, P.T., Paquette, R., Sawyers, C.L., DeAngelo, D.J., Gilliland, G.D., Stone, R., Caliguiri, M., Byrd, M.A., et al. 2002. A "first in man" study of the safety and PK/PD of an oral FLT inhibitor (MLN518) in patients with AML or high risk myelodysplasia. Proc. Am. Soc. Hematology Abstr.: 1305.

Heinrich, M.C., Corless, C.L., Demetri, G.D., Blanke, C.D., von Mehren, M., Joensuu, H., McGreevey, L.S., Chen, C.J., Van den Abbeele, A.D., Druker, B.J., et al. 2003a. Kinase mutations and imatinib mesylate response in patients with metastatic gastrointestinal stromal tumor. J. Clin. Oncol. (in press).

Heinrich, M.C., Corless, C.L., Duensing, A., McGreevey, L., Chen, C.J., Joseph, N., Singer, S., Griffith, D.J., Haley, A., Town, A., et al. 2003b. PDGFRA activating mutations in gastrointestinal stromal tumors. Science 299: 708-710.

Heitman, J., Movva, N.R., and Hall, M.N. 1991. Targets for cell cycle arrest by the immunosuppressant rapamycin in yeast. Science 253: 905-909.

Herbst, R.S., Maddox, A.M., Rothenberg, M.L., Small, E.J., Rubin, E.H., Baselga, J., Rojo, F., Hong, W.K., Swaisland, H., Averbuch, S.D., et al. 2002. Selective oral epidermal growth factor receptor tyrosine kinase inhibitor ZD1839 is generally well-tolerated and has activity in non-small-cell lung cancer and other solid tumors: Results of a phase I trial. I. Clin. Oncol. 20: 3815-3825.

Hirota, S., Isozaki, K., Moriyama, Y., Hashimoto, K., Nishida, T., Ishiguro, S., Kawano, K., Hanada, M., Kurata, A., Takeda, M., et al. 1998. Gain-of-function mutations of c-kit in human gastrointestinal stromal tumors. Science 279: 577-580.

Huang, H.S., Nagane, M., Klingbeil, C.K., Lin, H., Nishikawa, R., Ji, X.D., Huang, C.M., Gill, G.N., Wiley, H.S., and Cavenee, W.K. 1997. The enhanced tumorigenic activity of a mutant epidermal growth factor receptor common in human cancers is mediated by threshold levels of constitutive tyrosine phosphorylation and unattenuated signaling. I. Biol. Chem. 272: 2927-2935.

Inoki, K., Li, Y., Zhu, T., Wu, J., and Guan, K.L. 2002. TSC2 is phosphorylated and inhibited by Akt and suppresses mTOR signalling. Nat. Cell Biol. 4: 648-657.

Joensuu, H., Roberts, P.J., Sarlomo-Rikala, M., Andersson, L.C., Tervahartiala, P., Tuveson, D., Silberman, S., Capdeville, R., Dimitrijevic, S., Druker, B., et al. 2001. Effect of the tyrosine kinase inhibitor STI571 in a patient with a metastatic gastrointestinal stromal tumor. N. Engl. J. Med. 344: 1052-1056.

Kiyoi, H., Naoe, T., Yokota, S., Nakao, M., Minami, S., Kuriyama, K., Takeshita, A., Saito, K., Hasegawa, S., Shimodaira, S., et al. 1997. Internal tandem duplication of FLT3 associated with leukocytosis in acute promyelocytic leukemia. Leukemia Study Group of the Ministry of Health and Welfare (Kohseisho). Leukemia 11: 1447-1452. 
Levis, M., Allebach, J., Tse, K.F., Zheng, R., Baldwin, B.R., Smith, B.D., Jones-Bolin, S., Ruggeri, B., Dionne, C., and Small, D. 2002. A FLT3-targeted tyrosine kinase inhibitor is cytotoxic to leukemia cells in vitro and in vivo. Blood 99: $3885-3891$.

Libermann, T.A., Nusbaum, H.R., Razon, N., Kris, R., Lax, I., Soreq, H., Whittle, N., Waterfield, M.D., Ullrich, A., and Schlessinger, J. 1985. Amplification, enhanced expression and possible rearrangement of EGF receptor gene in primary human brain tumours of glial origin. Nature 313: 144-147.

Liotta, L.A., Espina, V., Mehta, A.I., Calvert, V., Rosenblatt, K., Geho, D., Munson, P.J., Young, L., Wulfkuhle, J., and Petricoin, E.F. 2003. Protein microarrays: Meeting analytical challenges for clinical applications. Cancer Cell 3: 317-325.

Lorusso, P.M. 2003. Phase I studies of ZD1839 in patients with common solid tumors. Semin. Oncol. 30: 21-29.

Ma, Y., Zeng, S., Metcalfe, D.D., Akin, C., Dimitrijevic, S., Butterfield, J.H., McMahon, G., and Longley, B.J. 2002. The cKIT mutation causing human mastocytosis is resistant to STI571 and other KIT kinase inhibitors; kinases with enzymatic site mutations show different inhibitor sensitivity profiles than wild-type kinases and those with regulatorytype mutations. Blood 99: 1741-1744.

Manning, B.D., Tee, A.R., Logsdon, M.N., Blenis, J., and Cantley, L.C. 2002. Identification of the tuberous sclerosis complex-2 tumor suppressor gene product tuberin as a target of the phosphoinositide 3-kinase/akt pathway. Mol. Cell 10: $151-162$.

Moss, K.G, Toner, G.C., Cherrington, J.M., Mendel, D.B., and Laird, A.D. 2003. Hair depigmentation is a biological readout for pharmacological inhibition of KIT in mice and humans. J. Pharmacol. Exp. Ther. 307: 476-480.

Nagar, B., Bornmann, W.G., Pellicena, P., Schindler, T., Veach, D.R., Miller, W.T., Clarkson, B., and Kuriyan, J. 2002. Crystal structures of the kinase domain of c-Abl in complex with the small molecule inhibitors PD173955 and imatinib (STI571). Cancer Res. 62: 4236-4243.

Nakao, M., Yokota, S., Iwai, T., Kaneko, H., Horiike, S., Kashima, K., Sonoda, Y., Fujimoto, T., and Misawa, S. 1996. Internal tandem duplication of the flt 3 gene found in acute myeloid leukemia. Leukemia 10: 1911-1918.

Neshat, M.S., Mellinghoff, I.K., Tran, C., Stiles, B., Thomas, G., Petersen, R., Frost, P., Gibbons, J.J., Wu, H., and Sawyers, C.L. 2001. Enhanced sensitivity of PTEN-deficient tumors to inhibition of FRAP/mTOR. Proc. Natl. Acad. Sci. 98: 10314-10319.

Neubauer, A., Brendel, C., Vogel, D., Schmidt, C.A., Heide, I., and Huhn, D. 1993. Detection of p53 mutations using nonradioactive SSCP analysis: p53 is not frequently mutated in myelodysplastic syndromes (MDS). Ann. Hematol. 67: 223226.

Okkenhaug, K., Bilancio, A., Farjot, G., Priddle, H., Sancho, S., Peskett, E., Pearce, W., Meek, S.E., Salpekar, A., Waterfield, M.D., et al. 2002. Impaired B and $T$ cell antigen receptor signaling in p1108 PI 3-kinase mutant mice. Science 297: 1031-1034.

Pegram, M., Hsu, S., Lewis, G., Pietras, R., Beryt, M., Sliwkowski, M., Coombs, D., Baly, D., Kabbinavar, F., and Slamon, D. 1999. Inhibitory effects of combinations of HER$2 /$ neu antibody and chemotherapeutic agents used for treatment of human breast cancers. Oncogene 18: 2241-2251.

Pietras, R.J., Fendly, B.M., Chazin, V.R., Pegram, M.D., Howell, S.B., and Slamon, D.J. 1994. Antibody to HER-2/neu receptor blocks DNA repair after cisplatin in human breast and ovarian cancer cells. Oncogene 9: 1829-1838.

Podsypanina, K., Lee, R.T., Politis, C., Hennessy, I., Crane, A.,
Puc, J., Neshat, M., Wang, H., Yang, L., Gibbons, J., et al. 2001. An inhibitor of mTOR reduces neoplasia and normalizes p70/S6 kinase activity in Pten ${ }^{+/}$mice. Proc. Natl. Acad. Sci. 98: 10320-10325.

Potter, C.J., Pedraza, L.G., and Xu, T. 2002. Akt regulates growth by directly phosphorylating Tsc2. Nat. Cell Biol. 4: 658-665.

Prados, M., Chang, S., Burton, E., Kapadia, A., Rabbitt, J., Page, M., Federhoff, A., Kelley, S., Fyfe, G., University of California San Francisco, and Genentech, Inc. 2003. Phase I study of OSI-774 alone or with temozolomide in patients with malignant glioma. Proc. Am. Soc. Clin. Oncology Abstr.: 394.

Rubin, B.P., Schuetze, S.M., Eary, J.F., Norwood, T.H., Mirza, S., Conrad, E.U., and Bruckner, J.D. 2002. Molecular targeting of platelet-derived growth factor B by imatinib mesylate in a patient with metastatic dermatofibrosarcoma protuberans. J. Clin. Oncol. 20: 3586-3591.

Salomon, A.R., Ficarro, S.B., Brill, L.M., Brinker, A., Phung, Q.T., Ericson, C., Sauer, K., Brock, A., Horn, D.M., Schultz, P.G., et al. 2003. Profiling of tyrosine phosphorylation pathways in human cells using mass spectrometry. Proc. Natl. Acad. Sci. 100: 443-448.

Sawyers, C.L. 1999. Chronic myeloid leukemia. N. Engl. J. Med. 340: $1330-1340$.

. 2002a. Finding the next Gleevec: FLT3 targeted kinase inhibitor therapy for acute myeloid leukemia. Cancer Cell 1: 413-415.

1. 2002b. Imatinib GIST keeps finding new indications: Successful treatment of dermatofibrosarcoma protuberans by targeted inhibition of the platelet-derived growth factor receptor. J. Clin. Oncol. 20: 3568-3569.

Sawyers, C.L. and Denny, C.T. 1994. Chronic myelomonocytic leukemia: Tel-a-kinase what Ets all about. Cell 77: 171-173.

Sawyers, C.L., Hochhaus, A., Feldman, E., Goldman, J.M., Miller, C.B., Ottmann, O.G., Schiffer, C.A., Talpaz, M., Guilhot, F., Deininger, M.W., et al. 2002. Imatinib induces hematologic and cytogenetic responses in patients with chronic myelogenous leukemia in myeloid blast crisis: Results of a phase II study. Blood 99: 3530-3539.

Schindler, T., Bornmann, W., Pellicena, P., Miller, W.T., Clarkson, B., and Kuriyan, J. 2000. Structural mechanism for STI-571 inhibition of abelson tyrosine kinase. Science 289: 1938-1942.

Schmelzle, T. and Hall, M.N. 2000. TOR, a central controller of cell growth. Cell 103: 253-262.

Shah, N.P. and Sawyers, C.L. 2003. Mechanisms of resistance to STI571 in Philadelphia chromosome-associated leukemias. Oncogene 22: 7389-7395.

Shah, N.P., Nicoll, J.M., Nagar, B., Gorre, M.E., Paquette, R.L., Kuriyan, J., and Sawyers, C.L. 2002. Multiple BCR-ABL kinase domain mutations confer polyclonal resistance to the tyrosine kinase inhibitor imatinib (STI571) in chronic phase and blast crisis chronic myeloid leukemia. Cancer Cell 2: 117-125.

Shai, R., Shi, T., Kremen, T.J., Horvath, S., Liau, L.M., Cloughesy, T.F., Mischel, P.S., and Nelson, S.F. 2003. Gene expression profiling identifies molecular subtypes of gliomas. Oncogene 22: 4918-4923.

Shamji, A.F., Nghiem, P., and Schreiber, S.L. 2003. Integration of growth factor and nutrient signaling: Implications for cancer biology. Mol. Cell 12: 271-280.

Shi, Y., Gera, J., Hu, L., Hsu, J.H., Bookstein, R., Li, W., and Lichtenstein, A. 2002. Enhanced sensitivity of multiple myeloma cells containing PTEN mutations to CCI-779. Cancer Res. 62: 5027-5034.

Shimizu, A., O’Brien, K.P., Sjoblom, T., Pietras, K., Buchdunger, 
E., Collins, V.P., Heldin, C.H., Dumanski, J.P., and Ostman, A. 1999. The dermatofibrosarcoma protuberans-associated collagen type I $\alpha 1 /$ platelet-derived growth factor (PDGF) Bchain fusion gene generates a transforming protein that is processed to functional PDGF-BB. Cancer Res. 59: 37193723.

Sill, H., Goldman, J.M., and Cross, N.C. 1995. Homozygous deletions of the p16 tumor-suppressor gene are associated with lymphoid transformation of chronic myeloid leukemia. Blood 85: 2013-2016.

Simon, M.P., Pedeutour, F., Sirvent, N., Grosgeorge, J., Minoletti, F., Coindre, J.M., Terrier-Lacombe, M.J., Mandahl, N., Craver, R.D., Blin, N., et al. 1997. Deregulation of the platelet-derived growth factor B-chain gene via fusion with collagen gene COL1A1 in dermatofibrosarcoma protuberans and giant-cell fibroblastoma. Nat. Genet. 15: 95-98.

Singer, S., Rubin, B.P., Lux, M.L., Chen, C.J., Demetri, G.D., Fletcher, C.D., and Fletcher, J.A. 2002. Prognostic value of KIT mutation type, mitotic activity, and histologic subtype in gastrointestinal stromal tumors. J. Clin. Oncol. 20: 38983905.

Sircar, K., Hewlett, B.R., Huizinga, J.D., Chorneyko, K., Berezin, I., and Riddell, R.H. 1999. Interstitial cells of Cajal as precursors of gastrointestinal stromal tumors. Am. J. Surg. Pathol. 23: 377-389.

Sommer, G., Agosti, V., Ehlers, I., Rossi, F., Corbacioglu, S., Farkas, J., Moore, M., Manova, K., Antonescu, C.R., and Besmer, P. 2003. Gastrointestinal stromal tumors in a mouse model by targeted mutation of the Kit receptor tyrosine kinase. Proc. Natl. Acad. Sci. 100: 6706-6711.

Stone, R.M., Klimek, V., DeAngelo, D.J., Nimer, S., Estey, E., Galinsky, I., Neuberg, D., Yap, A., Fox, E.A., Gilliland, D.G., et al. 2002. PKC412, an oral FLT2 inhibitor, has activity in mutant FLT3 acute myeloid leukema (AML): A phase II clinical trial. Proc. Am. Soc. Hematology Abstr.: 316.

Suzuki, H., Terauchi, Y., Fujiwara, M., Aizawa, S., Yazaki, Y., Kadowaki, T., and Koyasu, S. 1999. Xid-like immunodeficiency in mice with disruption of the $\mathrm{p} 85 \alpha$ subunit of phosphoinositide 3-kinase. Science 283: 390-392.

Tomasson, M.H., Williams, I.R., Hasserjian, R., Udomsakdi, C., McGrath, S.M., Schwaller, J., Druker, B., and Gilliland, D.G. 1999. TEL/PDGF $\beta R$ induces hematologic malignancies in mice that respond to a specific tyrosine kinase inhibitor. Blood 93: 1707-1714.

van Oosterom, A.T., Judson, I., Verweij, J., Stroobants, S., Donato di Paola, E., Dimitrijevic, S., Martens, M., Webb, A., Sciot, R., Van Glabbeke, M., et al. 2001. Safety and efficacy of imatinib (STI571) in metastatic gastrointestinal stromal tumours: A phase I study. Lancet 358: 1421-1423.

Vivanco, I. and Sawyers, C.L. 2002. The phosphatidylinositol 3-kinase AKT pathway in human cancer. Nat. Rev. Cancer 2: 489-501.

Weisberg, E., Boulton, C., Kelly, L.M., Manley, P., Fabbro, D., Meyer, T., Gilliland, D.G., and Griffin, J.D. 2002. Inhibition of mutant FLT3 receptors in leukemia cells by the small molecule tyrosine kinase inhibitor PKC412. Cancer Cell 1: 433-443.

Wellbrock, C., Garnett, M., and Marais, R. 2003. IL-16 B-Raf in melanoma. Pigment Cell Res. 16: 579.

Wong, A.J., Bigner, S.H., Bigner, D.D., Kinzler, K.W., Hamilton, S.R., and Vogelstein, B. 1987. Increased expression of the epidermal growth factor receptor gene in malignant gliomas is invariably associated with gene amplification. Proc. Natl. Acad. Sci. 84: 6899-6903.

Wong, A.J., Ruppert, J.M., Bigner, S.H., Grzeschik, C.H., Humphrey, P.A., Bigner, D.S., and Vogelstein, B. 1992. Structural alterations of the epidermal growth factor receptor gene in human gliomas. Proc. Natl. Acad. Sci. 89: 2965-2969.

Yang, J.C., Haworth, L., Sherry, R.M., Hwu, P., Schwartzentruber, D.J., Topalian, S.L., Steinberg, S.M., Chen, H.X., and Rosenberg, S.A. 2003. A randomized trial of bevacizumab, an anti-vascular endothelial growth factor antibody, for metastatic renal cancer. N. Engl. J. Med. 349: 427-434. 


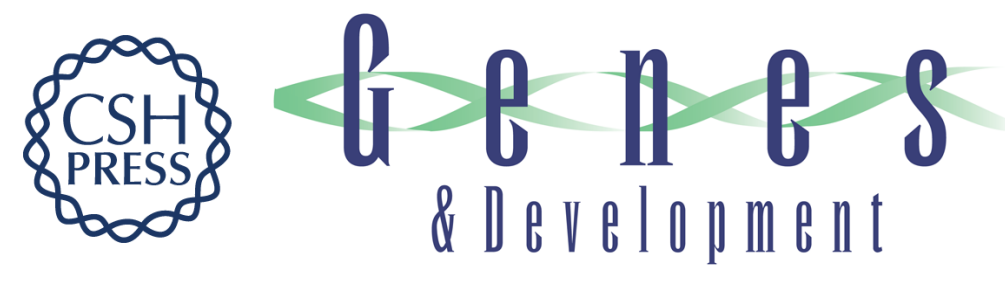

\title{
Opportunities and challenges in the development of kinase inhibitor therapy for cancer
}

\author{
Charles L. Sawyers
}

Genes Dev. 2003, 17:

Access the most recent version at doi:10.1101/gad.1152403

\section{References \\ This article cites 93 articles, 46 of which can be accessed free at: http://genesdev.cshlp.org/content/17/24/2998.full.html\#ref-list-1}

\section{License}

\section{Email Alerting}

Service

Receive free email alerts when new articles cite this article - sign up in the box at the top right corner of the article or click here.

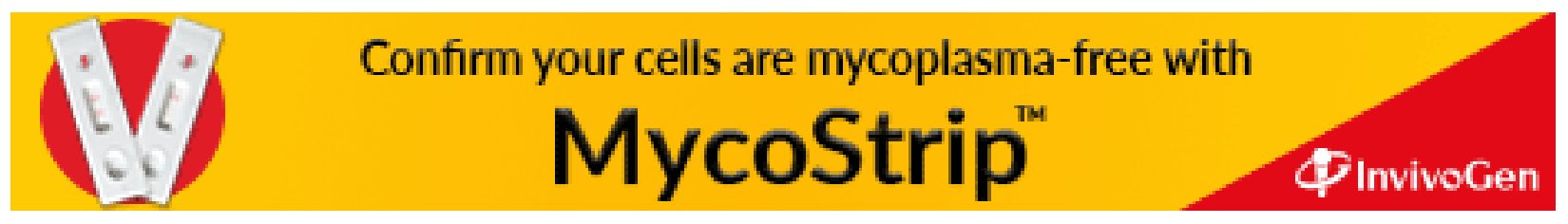

